University for Business and Technology in Kosovo

UBT Knowledge Center

UBT International Conference

2012 UBT International Conference

Nov 2nd, 9:00 AM - Nov 3rd, 5:00 PM

\title{
Bioclimatic Architecture of Residential Building in Kosovo
}

Mimoza Dugolli

University for Business and Technology, mdugolli@yahoo.com

Follow this and additional works at: https://knowledgecenter.ubt-uni.net/conference

Part of the Architecture Commons

\section{Recommended Citation}

Dugolli, Mimoza, "Bioclimatic Architecture of Residential Building in Kosovo" (2012). UBT International Conference. 7.

https://knowledgecenter.ubt-uni.net/conference/2012/all-events/7

This Event is brought to you for free and open access by the Publication and Journals at UBT Knowledge Center. It has been accepted for inclusion in UBT International Conference by an authorized administrator of UBT Knowledge Center. For more information, please contact knowledge.center@ubt-uni.net. 


\title{
Bioclimatic Architecture of residential buildings in Kosovo
}

\author{
Mimoza Dugolli ${ }^{1}$ \\ 1 University for Business and Technology (UBT), Prishtina, Kosovo, \\ Email:mdugolli@yahoo.com; mimoza.dugolli@ubt-uni.net
}

\begin{abstract}
The sustained Earth is our chain of the ecological survival. We have over used and over abused every material, every resource and every environmental attributes available for us, trying to find quick and easy solution to the problem. The general concern of modern word today is focused on creating the modern and clean living environment for its inhabitants. Kosovo, which is the newest state in the world, has a long road ahead to achieve the standards in order to create a healthy environment for its residents. A fast economic growth versus low possibility of energy production has caused concerns on Managing the Energy Demand in Kosovo. Among the biggest energy consumers in Kosovo are residential buildings which consume approximately $34 \%$ of the total energy produced. According to different researches the household energy demand will grow for 50\% until 2016. EU Directives and the need for Management of the Energy Demand will stress the importance of building regulations in helping to bring the improvements required not only for the new constructions but for the existing stock as well.
\end{abstract}

From this viewpoint, the questions that arise are:

Which measures could insure the decrease of energy consumption on the buildings with minimal additional investments? How can we reach human comfort and decrease energy consumption on the buildings with architectural components?

This paper outlines some of bioclimatic architecture techniques according to the Kosovo Climate and cost efficient measures to general architectural components that will give an opportunity to reach human comfort with low levels of energy consumption. The increased awareness of the architects, homeowners, and students in order to use the designs that perform well in its particular locations considering climate and microclimate components, to use sustainable materials and avoid the resource consumption, can make it possib le to decrease the energy consumption by the buildings up to $75 \%$.

Keywords: bioclimatic, architecture, energy, efficiency, techniques

\section{Introduction}

Today, the climates are changing. Global Climate change is reasoned by the accumulation of the greenhouses gases in the lower atmosphere. These changes will influent our political institutions and will create new concept of the human relationship and environment. The areas that require attention are:

Energy crisis - The disruption of energy supplies, it will increase of the energy price and the whole nation very soon will deal with this crisis.

Energy pollution - almost all energy production involves some kind of pollution, from fossil fuel to nuclear production of energy pollutes in a different way and different level that interfere human health and ecosystem. Greenhouse effect - the gasses created as natural blanket to the earth, increasing the overall temperature at $33^{\circ} \mathrm{C}$. Urban heat Islands - created on the cities with 1 million people or more. In the cities with high number of population, the temperature is $1-3^{\circ} \mathrm{C}$ higher than in rural parts while the differences during the night can go up to $12^{\circ} \mathrm{C}$.

On residential and commercial sector, the major part of energy consumption comes from the bu ildings. This includes energy used for controlling the climate in buildings and for the buildings themselves, but also energy used for appliances, lighting and other installed equipment. 


\section{Background}

Similar to all other parts of ex -Yugoslavia, Kosovo, from the year 1989 has faced a lot of challenges, changes that touched overall Kosovo society and had a big impact in the Kosovo's life.

Energy Sector in Kosovo is the integrated system of electricity that contains two lignite mines in Bardh and Mira sh, two lignite thermocentrales Kosovo A and Kosovo B with effective capacity of 645 to $710 \mathrm{MW}$, Network and Dispatching, Distribution and Supply Divisions.

The problems with the energy sector have to do with the insufficient amount of electricity and the energy pollution. Insufficient amount of electricity has a negative impact on social development. The highest level of energy consumption comes from residential buildings in Kosovo. For more, using the electricity for heating, during the winter period, raises a lot the energy consumption. It is counted that $64.2 \%$ of the total energy supplied in Kosovo, it is used for heating during the winter.

There are evaluated, as well, different scenarios of demographic growth and according to those analyses; the medium growth scenario will be up to $4 \%$ increase of the population until 2020 . The increase of energy demand requires the capital investments in generating capacities. Increasing the energy production also amplifies the sum of pollution emitted on the air.

Therefore managing the energy demand for the growing population and in the same time managing natural resources to reduce the negative effect on climate change will be the greatest challenge for Kosovo, in the future.

In this way, now more than ever, it is time to return to our point of origin, to deepen our understanding of the environment and correct our ways of living. It is time to focus on energy to come up with the appropriate means of utilizing our resources such as sunlight, wind, water and so on.

\section{New orientation}

The new orientation on architecture aims to move the human actions toward green to the large nature.

The new orientation aims the friendly relation of the natural and physical framework, the high level of organizing the energy consume within the building, the effectiveness of managing natural resources for human development and reduce the negative effects on climate change.

Therefore, there must be strategies to reduce the overheating and communities must be aware and take many steps to lower the temperature, reduce the energy consumption, and increase the physical comfort and quality of life.

Vegetated green roofs, living green walls, planting trees and vegetation employ the evapo-transpiration and evaporative-cooling procedures. $1 \mathrm{~m} 2$ of green areas can remove up to $2 \mathrm{~kg}$ airborne particulates from the air every day. Bioclimatic architecture combines interests of all approaches to evolve a solution for these requirements from the characteristic of the site, the local microclimate and topography.

The definition of the Passive bioclimatic architecture is based on two concepts;

The concept of satisfaction actually comprises needs and to get to the optimal positive life conditions and maximum life performances, by intelligent ideas (Al-Musaed, 2011).

The concept of limits of the environment capacity to fulfill the needs of the present and the future, to limit a high environment cost and get an earth more friendly and economic.

Bioclimatic architecture concerns itself with climate as a major contextual generator using minimal energy as its target. The one takes into account climate and environment conditions to help achieve comfort inside (Akbari, 2005).

\section{Kosovo Climatic Data}

Kosovo has a central geographical position in the Balkan Peninsula. In North geographical latitude lies between $41^{\circ} 50^{\prime}$ $58^{\prime \prime}$ and east geographical latitude on $20^{\circ} 01^{\prime} 30^{\prime \prime}$ and $21^{\circ} 48^{\prime} 02^{\prime \prime}$.

The average altitude of Kosovo is $810 \mathrm{~m}$, the lowest peak is $270 \mathrm{~m}$ and the highest peak is $2656 \mathrm{~m}$ (Gjeravica). In hypsometric terms area below $300 \mathrm{~m}$ altitude covers only $4.14 \mathrm{~km}^{2}(0.2 \%)$.

Up to $1000 \mathrm{~m}$ altitude includes $8754 \mathrm{~km}^{2}(80.7 \%)$. From 1000 to $2000 \mathrm{~m} 1872.3 \mathrm{~km}^{2}(17 \%)$ and above $2000 \mathrm{~m}$ altitude belong $250.6 \mathrm{~km}^{2}$ (2.3\%) of Kosovo territory. The main forms of relief in Kosovo are: Mountains $63 \%$ and hollow $37 \%$.

Kosovo is influenced of three main climatic characteristics:

- Climatic Zone in Kosovo Plain with impact of Aegean- Adriatic Climate, This is a reason why in this region the winters are colder with temperatures from $-10^{\circ} \mathrm{C}$, sometimes under $-26^{\circ} \mathrm{C}$. The summers are very hot, with average temperature $20^{\circ} \mathrm{C}$ and sometimes above $37^{\circ} \mathrm{C}$. This climate is characterized with a dry climate and annual precipitation around $600 \mathrm{~mm}$. 
- Climatic Zone in Dugagjini Plain, through the "Drini i Bardhe" plain with Adriatic Mediterranean Climate, which is influenced from hot air mass that comes from Adriatic Sea. The average temperature during the winter goes from $0.5^{\circ} \mathrm{C}$ up to $22.8^{\circ} \mathrm{C}$. Annual precipitation

- of this climatic zone is 700 mm per year. The winter is characterized with strong snow falls.

- Climatic Zone of Mountains and forests, with a typicalforests climate with strong precipitations from 900 up to $1300 \mathrm{~mm}$ per year. The summer is very short and cold and winters are long and with a lot of snow.

Kosovo's territory has good physical- geographical and topographical position. On the winter seas on the average of sunny days is above 5 hours, while annually is measured 2086.3 hours a year. Yearly the sky coverage with clouds is 66.1 hours. The country has a good potential of natural source of energy from wind and sun. During the year, 58\% is the frequency of the sunny days while the cloudy days are $32.9 \%$. The month with the clearest sky is August with $32 \%$ and the cloudiest is January with $76 \%$ (Tahirsylaj, 2010). According to the studies of the microclimate factors, Kosovo may be considered as a region with a combined climate.

\section{Energy balance on the buildings}

Energy is used in building for different purposes: heating and cooling, ventilating, heating sanitary water, lighting, etc. It is difficult to subdivide the buildings energy requirements; therefore the most analysis examines energy use in buildings as defined by end use: space heating, cooling, cooking, etc (Laustsen, 2008). Building-related end-uses heating, cooling, ventilation and the preparation of hot sanitary water - require approximately $75 \%$ of a total residential building's energy demand. Energy efficiency requirements in building standards can insure that this concern is taken on the early stage - design phase and can help to realize the large potentials for energy efficiency in new buildings.

For places with Combined Climate, it is very difficult to make a simplified comparison based only on heating degree days or cooling degree days in order to make an energy balance, as it is necessary to balance heat gains from the sun and internal resources with cooling and heating demands over the year.

Allowing solar penetration into the house during winter and reduce the heat gain during the summer are needed in order to balance heat and cooling needs.

Landscape: A well designing of surrounding landscape can be a good long term investment. Cautiously positioned trees can save up to $50 \%$ of a household's energy consumption for heating and cooling. The b ioclimatic architecture considers on its early design, the tools given from the nature. In the summer the process of evapo - transpiration and shading from trees can reduce air temperatures as much as $5^{\circ} \mathrm{C}$, in comparison with surrounding areas. In winter trees, fences or geographical features can be used as windbreaks to shield against cold winds (Al- Musajed 2011).

When choosing proper trees, for the climate in Kosovo, especially for domestic architecture it is necessary to consider the trees that give a light shades and medium shades (oaks, maples, ashes and linden). Light shades give the $3-4$ hours of shades which might be filtered sunlight, and medium shades that give shades 4-6 hours a day.

In Kosovo, light and medium shades trees, should be considered planting it mostly on the east and west sides, during the summer. While during the winter, when the heat from the sun is desirable, the plant will drop prematurely. For the south side, should be considered the length of the roof or a similar overhang designs.

When the plants are to be considered as a shelter, it is necessary to analyze the wind rose of specific city, like an example the wind rose for Pristine it is shown on the figure 1. According to the strongest wind direction should be decided for the tree sheltering. In Pristine, should be considered, as an example, sheltering especially on the north and northeast site of the building.

Ventilation: In the zones like Kosovo, cross ventilation and shielding are both necessary, for summer and winter respectively. The strategy for blocking or inducing the wind is based on local prevailing wind conditions. Energy in the building must be allocated throughout, regardless the thermal zones in the building. A well organized bioclimatic building recognizes the differences of thermal zones and creates them on different functional spaces. The group of functions which is considered to have approximately the same internal temperature should be assembled, while the group of function that creates higher temperature should be splitter on the periphery of the building. Depending from the climatic zone, it should be treated and considered the movement of hot and cold air, from inside to outside for natural ventilation and heating. Ventilation is usually combined with energy conservation measures like shading provided by trees, window treatment, etc Ventilation has many benefits besides cooling. It can save money, when you ventilate a home instead of using air/condition. Not using the air/condition has its positive impact on the environment. For more, in homes with poor ventilation inside, air pollutant tend to accumulate. 
Natural ventilation relies on the wind and chimney effect to keep a home cool. A cross ventilation standard is similar to all natural ventilation philosophy. This can be created by opening the windows and doors and adjusting the size and location of the openings to ventilate different parts of the home. Inlet and outlets being opposite to each other will cool only the area in between. If we force a wind to take a longer path from the inlet to outlet we will be able to ventilate more space. Windows positioned to outside shaded area will make it possible to bring fresher and cooler air inside.

Fig 1: Pristine wind rose (Tahirsylaj, 2010)

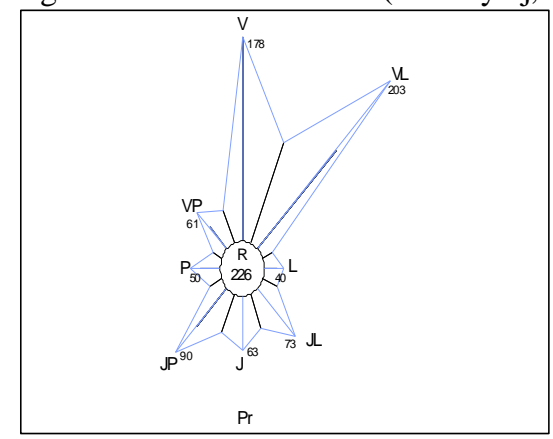

In the Pristine climate for example, from the wind rose we can see that the strongest winds come from the north and north-east side. Therefore using the practice for ventilation, as described above, the small windows installed on the north and north-east will make it possible to ventilate the air inside with the opposite side on the south-west bigger windows.

Fig. 2: Cros-ventilation, small wind innlet ( Adapted from Al-Musaed 2011)

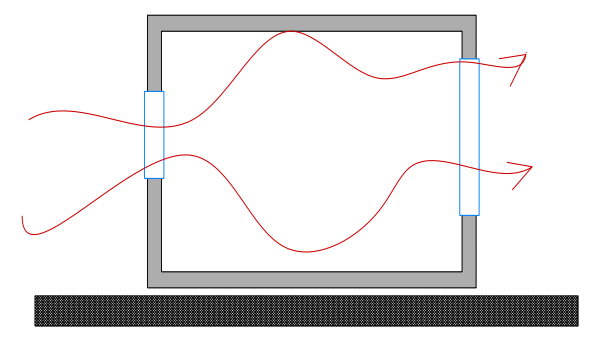

Wing walls or exterior vertical fins can increase a buildings ventilate potential by catching and deflecting wind into the interior.

It can increase ventilation rates when the wind incidence angle is perpendicular to the building face. One of the most useful effects of wing walls is the creation of the cross ventilation in the rooms with one window only or in rooms without positive pressure inlets and negative pressure outlets. Proper placement of wing walls can create positive and negative pressure zones which allow ventilation in rooms which would otherwise remain stagnant.

Heating: Basic bioclimatic design principles include orientation of windows relative to the position of the sun, thermal mass, natural ventilation and sunlight and shading areas. An essential element for the implementation of the concept is orientation of the field energy toward energy sources, especially direct and indirect use of the solar energy (Al-Musaed 2004). Passive heating is usually achieved through two types of phenomenon:

- Greenhouse phenomenon, which is a source of energy that architects, can use it for temperate climates, like in Kosovo.

- Thermodynamics phenomenon, which is achieved when two same materials are placed together, they will exchange the temperature between them until the temperature is the same for both of them.

Windows: Windows are extremely influential factor in climatic design, as the weakest climatic element of the building envelope. For more, the windows have an important psychological function: they expose the users to the environment. The arrangement of window openings is necessary, in order to use all the ranges of the view: the direct environment, vegetation and roads, building, landscape, horizon and the sky. Their orientation requests a specific analyze as well. Every cardinal point has its own characteristics. 
In Kosovo during the summer all the windows receive net heat gains, especially those facing east and west, in the morning and afternoon. Heat gain is a resultant of a green house effect. This can be an advantage in winter but can create overheat in summer. Therefore for summer should be avoided by shading glass from the direct rays of the sun. External shading devices are an effective way to reduce heat gain through windows in summer and keep building cool. External shades reduce around 79\% heat gain. Permanent shading includes structures like attic, pergolas, or verandas, so they are typically part of the building construction, but always respecting the necessity of using solar heat during the winter. Depending on the season and the sun's path, properly designed overhangs can protect south-facing windows and other surfaces from high angle summer sun, while allowing heat from lower angle winter sun to penetrate into the house. Overhang design depends on the location of solar south, the building site's latitude, and the length of the heating and cooling season. It is very important to know the solar south. Solar south is different than magnetic south. The solar south takes it into consideration the sun's path. The depth of the overhang will depend on the North latitude of the building. Calculating proper depth of the overhang ensures proper indoor shading during the summer and solar heat gain during the winter. Determining the solar noon for city of Pristine, for example, is as follows:

On June 21, sunrise is at 4:51 a.m. and sunset is at 8:15 p.m.

There are fifteen daylight hours, plus 24 additional minutes,

(Number of daylight hours) multiplied by 60;15 x $60=900$

(Number of daylight minutes from hours ) + (additional daylight minutes); $900+24=924$

(Number of total daylight minutes) divided by $2 ; 924 / 2=462$

(Midpoint of total daylight minutes) divided by 60; $462 / 60=7.7$

Sub strict the number of hours 7.7-7 $=0.70$

Multiply the remaining minute's fraction by $60 ; 0.70 \times 60=42$

Solar noon is 7 hours and 42 minutes later than sunrise: $4: 51+7: 42=\mathbf{1 2 : 5 5}$

Therefore the solar noon for Pristine is at 12:55 am

At solar noon, for the particular date, should be found the flattest outdoor surface on the south side of the lot of the building. First step is: taking two stakes, placing one on the ground at exactly solar noon, and the second stake, placing at the end of the shadow of the first stake. Tying a string between the two stakes, we will be able to provide the north- south axis of the building.

By placing the next two stakes on the ground, second string will be directly perpendicular to first string. Next step is to tie the second piece of string around the remaining two stakes. This perpendicular line to the original north/south axis will give us the desired southern exposure (east / west axis). For maximum passive solar benefits, building / windows should be parallel with the east/west line, facing solar south.

Fig. 3 Solar south (Adapted from Hawks, Peterson, Sowards, 2005)

The depth of the overhang will depend on the North latitude of the building. For Kosovo case, characterized with temperate climate, most important is to calculate the south facing overhang.

Roughly appropriate overhang dimension W can be calculated by selecting the Shade Line Factor (SLF), which is an constant factors calculated according to the North Latitude, and inserting on the formula (Source: Brown, Mark 2001).

W (overhang dimension) $=$ H / SLF

Fig. 4 Overhang dimensions (Source: Brown, Mark 2001) 


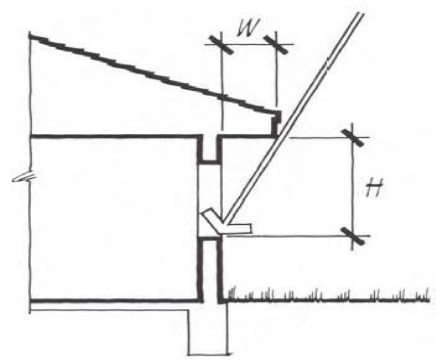

Example, for the window high $150 \mathrm{~cm}$, the overhang dimension is $68.18 . \mathrm{cm}$. Therefore, in this case, overhang will insure heat gain during the winter months and proper shadow during the summer months.

\section{Conclusions}

The climate changes due to the environmental pollution are a worldwide concern and being one of the countries that its objective is to be part of modern world and ensuring a healthy life to its citizens, the climate changes are an important is sue to Kosovo as well.

Energy production is one on the sectors that contribute mostly on the pollution. The major part of energy consumption have buildings, therefore the improvements on architectural projecting principals are necessary.

Therefore we conclude that using the information of the climate factors regarding the wind, light, sun and shadows, in order to achieve the inside home inhabitants comfort, without using high amount of energy for cooling, heating and ventilation, is very critical at this point.

The increased awareness of the architects, homeowners, and students in order to use the designs that perform well in its particular locations considering climate and microclimate components, can make it possible to decrease the energy consumption by the buildings.

The Kosovo Institutions should set, enforce and regularly update the Building Code (compatible to EU) for Kosovo, considering its local condition and overall country objectives.

Government should set a package of initiatives to address the barriers and implement the requirements that comes from the legislation for energy and environment, especially for energy efficiency in new and existing buildings.

Research and developments should be supported as well, by the local and central Government to develop intelligent design of highly energy efficiency buildings.

\section{References}

Al-Musaed A., (2004), Intelligent sustainable strategies upon passive bioclimatic houses, Arkitektskole in Aarhaus, Aarhus, Denmark.

Al-Musaed, A. (2011), Biophilic and Bioclimatic Architecture, Springer, London.

Akbari H., (2005), Energy saving potentials and air quality benefits of urban heat is lands mitigation, Lawrence Berkeley National Laboratory, Berkeley.

Brown, G.Z. and DeKay Mark (2001), Sun, Wind \& Light: Architectural Design Strategies, John Wiley \& Sons, New York.

Laustsen J., (2008), Energy efficiency requirements in building codes, IEA.

Dugolli, M. (2012): Bioclimatic Architecture and Home Automation, Case Study: Residential Buildings in Kosovo, PhD Thesis, Technical University of Vienna, Austria.

Tahirsylaj S. (2011c), Annual average of sunny days per year, Official Data from Meteorological Institute of Kosovo, Prishtina. 